\title{
Diaphragmatic Mobility Loss in Subjects With Moderate to Very Severe COPD May Improve After In-Patient Pulmonary Rehabilitation
}

\author{
Camilo Corbellini PhD PT, Alain Boussuges MD PhD, Jorge Hugo Villafañe PhD PT, and \\ Luciano Zocchi MD PhD
}

\begin{abstract}
BACKGROUND: The diaphragm changes in COPD lead to functional inefficiency correlated to lung function loss. Muscle-fiber shortening follows lung hyperinflation, which results in a chronic mechanical disadvantage that impairs diaphragmatic mobility that worsens in COPD exacerbations. OBJECTIVES: To correlate the diaphragmatic mobility loss to COPD severity by using M-mode ultrasonography and to verify if the diaphragmatic mobility can improve after in-patient pulmonary rehabilitation. METHODS: We used M-mode ultrasonography to access diaphragmatic mobility during normal breathing or breathing at rest and deep inspiration in 52 subjects with moderate to very severe COPD who underwent pulmonary rehabilitation and 16 healthy subjects. Lung function test, arterial blood gas analysis, and a 6-min walk test were also performed. The measurements were performed at rehabilitation admission and discharge. RESULTS: We screened 30 subjects with severe to very severe COPD who had completed pulmonary rehabilitation. At discharge, inspiratory capacity improved, from $1.58 \pm 0.5 \mathrm{~L}$ to $1.7 \pm 0.6 \mathrm{~L}(P=.04)$. Diaphragmatic mobility during deep inspirations increased from (mean \pm SD) $4.58 \pm 1.83 \mathrm{~cm}$ to $5.45 \pm 1.56 \mathrm{~cm}$ $(P=.05)$ after pulmonary rehabilitation. The diaphragmatic mobility during rest breathing was higher in the subjects with COPD $(2.25 \pm 0.83 \mathrm{~cm})$ than in the healthy subjects $(1.27 \pm 0.3 \mathrm{~cm})$ $(P=.01)$. The diaphragmatic mobility for the rest breathing and deep inspirations were correlated to an $\mathrm{FEV}_{1}$ decrease $(\mathrm{r}=-0.74, P<.001$; and $\mathrm{r}=0.8, P<.001$, respectively). CONCLUSIONS: Our findings demonstrated diaphragmatic mobility loss in the subjects with moderate to very severe COPD. These changes were correlated with COPD severity, and diaphragmatic mobility loss improved after in-patient pulmonary rehabilitation. (ClinicalTrial.gov registration NCT02838953.) Key words: diaphragm; rehabilitation; ultrasonography; COPD; lung function; dynamic hyperinflation. [Respir Care 2018;63(10):1271-1280. (C) 2018 Daedalus Enterprises]
\end{abstract}

\section{Introduction}

COPD is a pathology that alters diaphragmatic anatomy and structure. ${ }^{1}$ The main concern with COPD is air-flow

\footnotetext{
Dr Corbellini is affiliated with the Department of Pulmonary Rehabilitation, Casa di Cura Villa Serena, SpA, Piossasco, Italy. Dr Boussuges is affiliated with UMR-MD2 Dysoxie Suractivité, Institut de Recherche Biomédicale des Armées and Aix-Marseille Université, Marseille, France. Dr Villafañe is affiliated with Istituto di Ricovero e Cura a Carattere Scientifico, Don Gnocchi Foundation, Milan, Italy. Dr Zocchi is affiliated with the Section of Human Physiology, Department of Pathophysiology and Transplantation, Università degli Studi di Milano, Milan, Italy.
}

obstruction, not fully reversible, and associated with systemic inflammation. The progressive alterations of airways and parenchyma decreases lung elastic recoil and

\footnotetext{
Dr Corbellini presented a version of this article at the European Respiratory Society Congress held 3 to 7 September 2016, in London, United Kingdom.

The authors have disclosed no conflicts of interest.

Correspondence: Camilo Corbellini PhD PT, Casa di Cura Villa Serena, SpA, Department of Pulmonary Rehabilitation, Via Magenta 45, Piossasco, Italy 10045. E-mail: camilocorbellini@ hotmail.com.
}

DOI: $10.4187 /$ respcare. 06101 
impairs gas exchanges. ${ }^{2-4}$ These changes and subsequent lung hyperinflation increase the respiratory work load. ${ }^{5}$ In patients with severe hyperinflation, the diaphragm is flatter and lower than in normal individuals. The apposition zone to the rib cage is reduced, and, during inspiration, the diaphragmatic dome descends less than in normal subjects, which results in a reduced expansion of the lower rib cage. ${ }^{6,7}$ Furthermore, in patients with COPD, both oxidative stress and the systemic inflammatory process lead to general muscular atrophy, including structural changes of the diaphragm. Diaphragmatic muscle fibers lose myosin, the sarcomeres become shorter, and the muscular crosssectional area reduces. ${ }^{1}$ An increase in the number of type I fibers to the detriment of type II fibers has also been reported. 8,9

The diaphragm anatomy does not permit a wide range of techniques to assess its function. Radiography, fluoroscopy, and magnetic resonance imaging have been used to evaluate this muscle for assessment of mobility and function. Ultrasonography has many advantages over these techniques, such as the lack of ionizing radiation and the possibility of using ultrasonography at the patient's bedside. Furthermore, it is an inexpensive technique, requires a small time investment, ${ }^{10}$ and is already used to diagnose diaphragmatic rupture or thickness, pleural masses, and pulmonary effusions. ${ }^{11}$ Ultrasonography in the M-mode can assess diaphragmatic kinetics, which directly measures the dome craniocaudal displacement, which is more visible on the right diaphragmatic side. ${ }^{12-14}$ Such measurements can be useful to assess the impact of both lung hyperinflation and diaphragmatic fiber structural changes on the diaphragmatic motion in patients with COPD.

For patients with COPD, the interest of pulmonary rehabilitation has been clearly demonstrated, and the most frequent outcomes in the current literature are the reduction of dyspnea, increase in exercise capacity, and improvement in quality of life. ${ }^{15}$ Pulmonary rehabilitation is a complex intervention based on multidisciplinary patient assessment and focused on exercise training, education, and behavior modification. Pulmonary rehabilitation has been reported to significantly improve inspiratory muscle strength and exercise capacity, and to decrease dynamic lung hyperinflation and dyspnea. ${ }^{16,17}$ Furthermore, it has been demonstrated that diaphragmatic impairment impacted dyspnea and exercise tolerance, ${ }^{18}$ and was correlated with $\mathrm{P}_{\mathrm{aCO}}$, airway obstruction, and air trapping in subjects with COPD. ${ }^{19,20}$ Consequently, we could hypothesize that, in patients with COPD, diaphragmatic motion increases after in-patient pulmonary rehabilitation. In the present study we assessed, by using M-mode ultrasonography, the correlation between the diaphragmatic mobility to lung function decreasing, and we also verified the pulmonary rehabilitation effect in the diaphragmatic mobility in a cohort of subjects with COPD.

\section{QUICK LOOK}

\section{Current knowledge}

COPD impairs diaphragmatic anatomy, structure, and function. Diaphragmatic mobility can be easily assessed by using M-mode ultrasonography without exposing the patient to any risk, and it can be easily performed even during pulmonary rehabilitation.

\section{What this paper contributes to our knowledge}

Diaphragmatic mobility was dramatically impaired in the subjects with COPD compared with the healthy subjects. This reduction was correlated to lung function deterioration, and improvements in dynamic lung hyperinflation after pulmonary rehabilitation may improve diaphragmatic motion.

\section{Methods}

All the subjects with COPD admitted to the rehabilitation center, Casa di Cura Villa Serena, Piossasco, Italy, from March 2016 to September 2016, and 16 healthy volunteers were prospectively included. All the subjects signed an informed consent. We excluded patients with a history of pneumothorax (treated within the last $12 \mathrm{wk}$ ), hemoptysis, acute heart failure, pulmonary embolism, hypertension, aneurysm, hepatic surgery, splenectomy, diaphragmatic paralysis, and neuromuscular diseases.

The subjects with COPD underwent a standard evaluation, including lung function tests (spirometry and body plethysmography, and the determination of lung diffusion of carbon monoxide), a 6-min walk test, and arterial blood gas analyses. The lung function tests were performed by using QUARK PFT Plethysmography (COSMED, Rome, Italy), according to the standards determined by the American Thoracic Society/European Respiratory Society task force. ${ }^{21-25}$ The subjects also performed the 6-min walk test according to the American Thoracic Society/European Respiratory Society statements. ${ }^{26,27}$ Arterial blood sampling was performed under the direction of a physician for arterial blood gas analyses.

Within the second day in the rehabilitation center, diaphragmatic mobility was assessed by ultrasonography as follows. The subjects were positioned in a semi-recumbent position $\left(45^{\circ}\right)$. The ultrasonography probe was positioned between the anterior and mid axillary lines, on the central right subcostal area, cranial and dorsal. The ultrasounds were performed perpendicular on the posterior hemidiaphragm third (it was visualized as the hyperechogenic line behind the liver). Diaphragmatic mobility was assessed by using the M-mode while the patient breathed during rest breathing and during deep inspiration. 

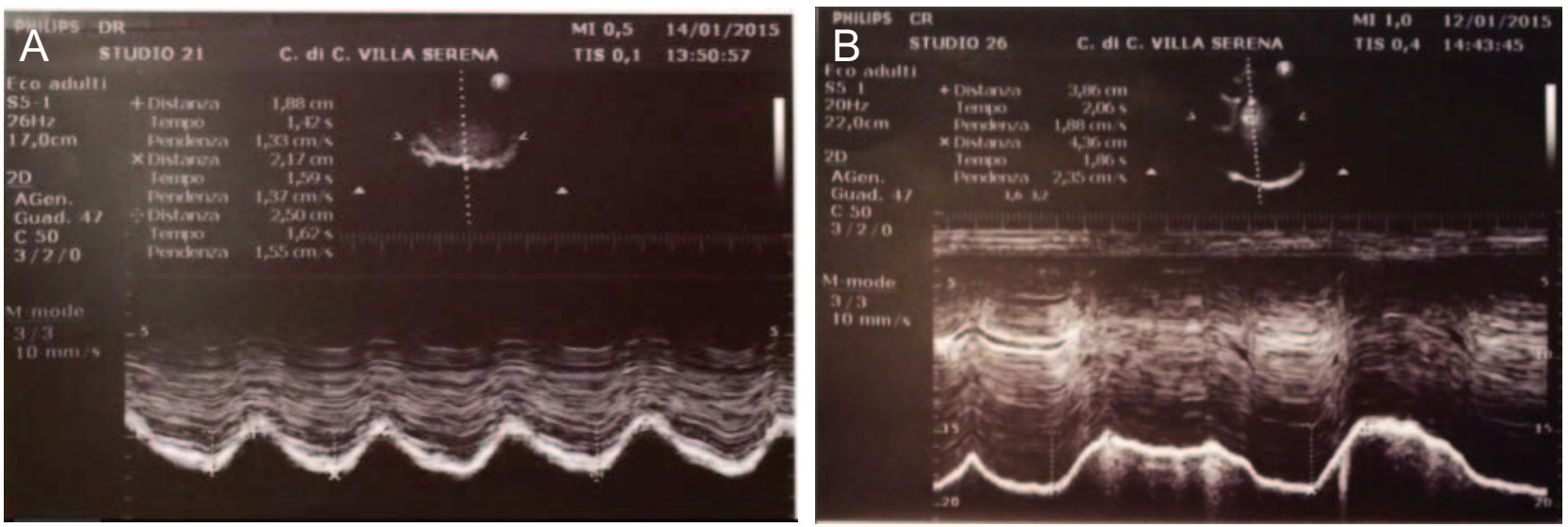

Fig. 1. Diaphragmatic M-mode ultrasonography on resting breathing (mean mobility, $2.18 \mathrm{~cm}$ ) of a subject with severe $\left.\mathrm{COPD}_{(\mathrm{FEV}}=0.38\right)$ $(A)$; the deep inspiration (higher movement, $4.36 \mathrm{~cm}$ ) from a different subject with severe $\left.\mathrm{COPD}_{(\mathrm{FEV}}=0.50\right)(\mathrm{B})$.
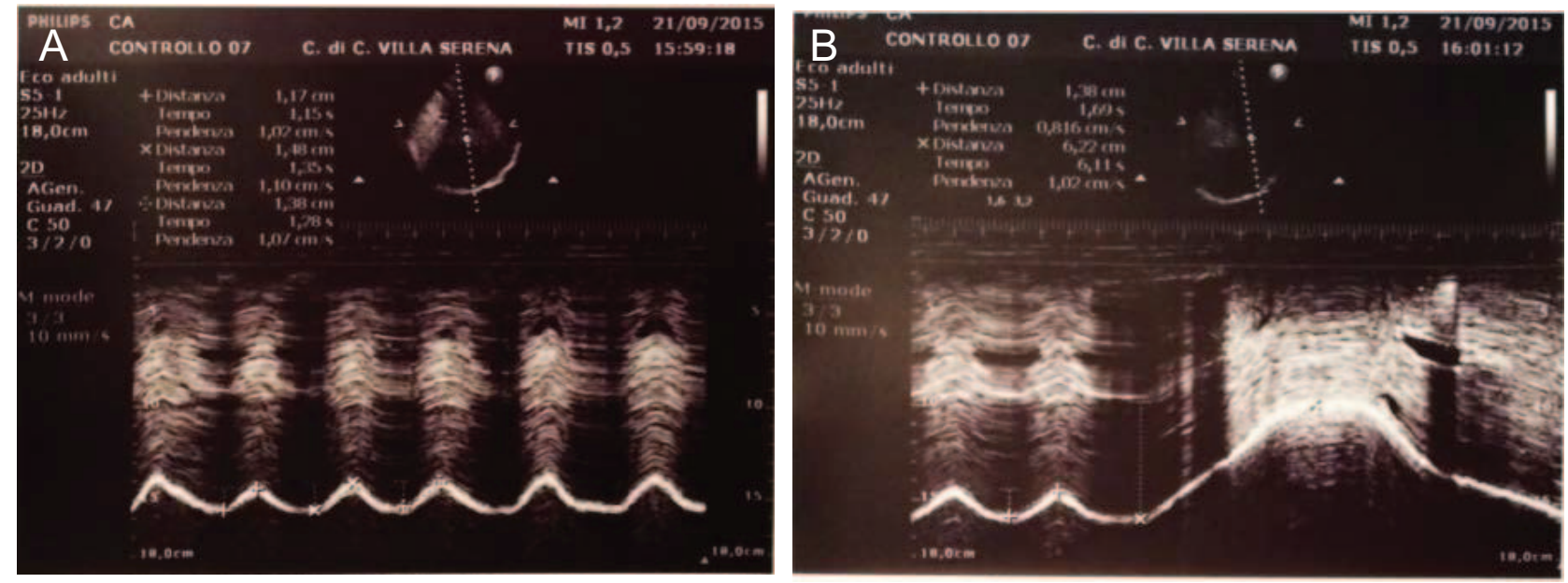

Fig. 2. Diaphragmatic M-mode ultrasonography on healthy controls. At rest breathing (mean mobility, $1.25 \mathrm{~cm})(\mathrm{A})$; deep inspiration $(6.11 \mathrm{~cm})(\mathrm{B})$.

The diaphragmatic amplitudes were determined by placing the first caliper at the foot of the inspiration slope on the diaphragmatic echoic line, and the second caliper was placed at the apex of this slope. Resting breathing (on tidal volume) was measured and recorded during several cycles, and was considered the mean slope amplitude (Figs. 1 and 2, left panels). For deep inspiration, several slopes were also measured and recorded, and the higher distance between the apex to the base was retained (Figs. 1 and 2, right panels). For this maneuver, the patient was requested to, at the end of the resting expiratory breath, do a maximal inspiratory effort, inspiring as slowly and deeply as possible. For those measurements, a portable CX50 compact ultrasound system (Amsterdam, Netherlands) Philips was used.

The subjects with COPD were classified according to the Global Initiative for Chronic Obstructive Lung Disease criteria for the severity of airway obstruction. ${ }^{2} \mathrm{Ev}-$ ery subject, after assessment, followed the pulmonary rehabilitation of the American Thoracic Society/European Respiratory Society statement on pulmonary rehabilitation. ${ }^{28}$ All the subjects followed a routine of $5 \mathrm{~d} / \mathrm{wk}$ of physical exercise, divided into 2 sections of 1 hour each. Pulmonary rehabilitation consisted of $30 \mathrm{~min}$ of calisthenic gymnastics once a day and 30 min of aerobic cycloergometer training twice a day. The aerobic cycloergometer training was set at $60-70 \%$ of the maximum heart rate determined by equation 220 minus the subject's age. The subjects also performed lower-limb strengthening exercises. During the in-hospital stay, the subjects received regular prescribed medication and oxygen therapy according to their medical prescriptions. The subjects also received respiratory physiotherapy with regard to the presence of lung secretion retention and the need to expand unventilated areas.

A healthy volunteer group was composed to establish normal values for diaphragmatic mobility and to correlate 
the loss of lung function to diaphragmatic mobility modifications. Subjects without a history of chronic lung disease and with an $\mathrm{FEV}_{1}: \mathrm{FVC}$ of $>0.70$ were included in this group; they all had the same lung function tests and M-mode ultrasonography.

\section{Statistical Analyses}

The qualitative data were presented as percentages and frequency. The quantitative data were described as mean \pm SD for the symmetrical distributions. We used the Kolmogorov-Smirnov test to determine distribution means and normality. The Bonferroni test was used post hoc to evaluate statistical significance. Within-group effect sizes were calculated by using the Cohen $\mathrm{d}$ coefficient interpretation. For all study data, $P<.05$ were considered significant. We used the Student $t$ test for the independent sample for quantitative data and for comparisons between the subjects with COPD and the healthy subjects, and analysis of variance for comparisons within the COPD group. We used the Pearson correlation test to measure the correlation between diaphragmatic mobility and lung function. Data were analyzed by using SPSS package version 20.0 (SPSS, Chicago, Illinois).

\section{Ethical Aspects}

Informed consent was obtained from all the participants, and the procedures were conducted according to the Declaration of Helsinki, ${ }^{29}$ and according to Italian laws for the subjects with respect to their privacy and data confidentiality (D.L. 196/2003). The protocol was approved by the ethics committee from the Piedmont health system (40/2016).

\section{Results}

From March to September 2016, 52 consecutive subjects $(13$ women) underwent the first assessment. Two subjects were excluded, one presented with an inverted contraction of the diaphragm and another died during the hospitalization. Of the 46 subjects who fit the inclusion criteria (FVC:FEV $1<0.70), 16$ did not complete the protocol (4 strokes, 6 myocardial infarction, 4 cardiogenic pulmonary edema, and 2 thrombophlebitis). In addition, 16 healthy volunteers underwent a protocol, including spirometry and ultrasonographic examination.

The mean \pm SD length of stay was $31 \pm 8 \mathrm{~d}$. At the beginning of pulmonary rehabilitation, the subjects with COPD presented with severe airway obstruction and lung hyperinflation, and with a severe reduction of carbon monoxide lung diffusion, and they walked $50 \%$ of their predicted distance for the 6-min walk test. Their mean \pm SD diaphragmatic mobility was $2.09 \pm 0.8 \mathrm{~cm}$ for rest breath- ing and $4.75 \pm 1.58 \mathrm{~cm}$ for deep inspiration. Described in Table 1 are the characteristics for anthropometry, lung function tests, and diaphragmatic ultrasonography for subjects with COPD and the healthy subjects. Also, the differences for diaphragmatic mobility between the healthy individuals and the subjects with COPD, classified according to air-flow limitation severity, are presented in Table 1 . The 16 healthy individuals presented with normal pulmonary function testing values. Diaphragmatic mobility for rest breathing was $1.27 \pm 0.3 \mathrm{~cm}$, and the mean $\pm \mathrm{SD}$ diaphragmatic mobility for the deep inspiration until the total lung capacity was $6.93 \pm 1.15 \mathrm{~cm}$. We observed that there was a significant statistical difference between the mean diaphragmatic mobility at both rest breathing and deep inspiration between healthy individuals and the subjects with COPD. The results for the 6-min walk test in the subjects with COPD are presented in Table 2.

Diaphragmatic mobility during rest breathing was higher in the subjects with COPD when compared with the healthy individuals. In contrast with this finding, diaphragmatic mobility for the deep inspiration was lower in the subjects with COPD. The inspiratory capacity was lower in the subjects with COPD when compared with the healthy individuals. This difference was significant in all COPD groups (Table 1), and the inspiratory capacity improved for all the subjects with COPD (Table 3).

The correlation of $\mathrm{FEV}_{1} \%$ predicted and diaphragmatic mobility during rest breathing $(\mathrm{r}=-0.74, P<.001)$ and deep inspiration $(\mathrm{r}=0.796, P<.001)(n=45)$ are demonstrated in Figure 3. The correlation between diaphragmatic mobility and the lung function test was also positive between deep inspiration and the inspiratory capacity $(\mathrm{r}=0.64, P<.001)$ and the expiratory reserve volume $(\mathrm{r}=0.63, P<.001)(n=45)($ Fig. 4$)$. Diaphragmatic mobility correlations between rest breathing and deep inspiration and the inspiratory capacity to total lung capacity ratio were both moderate but negative $(\mathrm{r}=-0.51$, $P=.01)$ and positive $(\mathrm{r}=0.50, P=.01)$ presented in Figure 5.

The impact of pulmonary rehabilitation on diaphragmatic mobility in all the subjects with COPD was assessed by comparing the mean variables measured before and after pulmonary rehabilitation. Diaphragmatic mobility during rest breathing was unchanged in the subjects with COPD after pulmonary rehabilitation. However, an improvement of diaphragmatic mobility $(P=.01)$ during deep inspiration was observed after pulmonary rehabilitation. This improvement was associated with an increase in the inspiratory capacity $(P=.040)$. The arterial blood gas analyses results did not present any statistic significant improvement (Table 3).

The intraclass correlation coefficient for intra-examiner reliability for the measurements of the diaphragmatic mobility in rest breathing for all the subjects who completed 


\section{Pulmonary Rehab for Diaphragmatic Mobility Loss}

Table 1. Anthropometric Data, Lung Function Test, 6-Min Walk Test, and Diaphragmatic Ultrasonography, All Subjects With COPD and According to the Airflow Limitation Severity

\begin{tabular}{|c|c|c|c|c|c|}
\hline \multirow[t]{2}{*}{ Variable } & \multirow{2}{*}{$\begin{array}{l}\text { Healthy } \\
\text { Individuals } \\
(n=16)\end{array}$} & \multirow{2}{*}{$\begin{array}{l}\text { All Subjects } \\
\text { With COPD } \\
\quad(n=46)\end{array}$} & \multicolumn{3}{|c|}{$\begin{array}{l}\text { Subjects With COPD Who Completed the } \\
\text { Pulmonary Rehabilitation, and According to } \\
\text { the Airflow Limitation Severity }(n=30)\end{array}$} \\
\hline & & & GOLD 2 & GOLD 3 & GOLD 4 \\
\hline \multicolumn{6}{|l|}{ Anthropometric data } \\
\hline Subjects, $n$ (women) & $16(9)$ & $46(11)$ & $6(0)$ & $13(6)$ & $11(1)$ \\
\hline Age, mean \pm SD y & $34 \pm 9$ & $72 \pm 10$ & $76.5 \pm 7$ & $70 \pm 8$ & $65 \pm 15$ \\
\hline Weight, mean \pm SD kg & $74 \pm 32$ & $61.5 \pm 11.5$ & $71.2 \pm 13.7$ & $62 \pm 15$ & $57.8 \pm 10.6$ \\
\hline Height, mean $\pm \mathrm{SD} \mathrm{m}$ & $1.62 \pm 26$ & $1.62 \pm 9.3$ & $1.66 \pm 9$ & $1.60 \pm 8$ & $1.61 \pm 7.5$ \\
\hline $\mathrm{BMI}$, mean $\pm \mathrm{SD} \mathrm{kg} / \mathrm{m}^{2}$ & $22 \pm 6$ & $23.5 \pm 4.3$ & $25.8 \pm 5.5$ & $24.1 \pm 5$ & $22 \pm 4.5$ \\
\hline \multicolumn{6}{|l|}{ Lung function, mean $\pm \mathrm{SD}$} \\
\hline FVC, L & $4.75 \pm 14$ & $2.11 \pm 0.6$ & $2.88 \pm 0.56$ & $1.96 \pm 0.4$ & $1.8 \pm 0.5$ \\
\hline FVC $\%$ pred & $106 \pm 30$ & $72 \pm 17$ & $88.6 \pm 8.6$ & $71.4 \pm 12.8$ & $57 \pm 13$ \\
\hline $\mathrm{FEV}_{1}, \mathrm{~L}$ & $4.04 \pm 1.36$ & $0.88 \pm 0.36$ & $1.46 \pm 0.2$ & $0.82 \pm 0.11$ & $0.5 \pm 0.1$ \\
\hline $\mathrm{FEV}_{1} \%$ pred & $103 \pm 30$ & $40.6 \pm 16$ & $60 \pm 7$ & $38.5 \pm 5.7$ & $21.7 \pm 4$ \\
\hline FVC:FEV 1 & $78 \pm 20$ & $41.7 \pm 11.4$ & $51.42 \pm 6.5$ & $43.6 \pm 9.5$ & $30 \pm 4.6$ \\
\hline $\mathrm{FEF}_{25-75}, \mathrm{~L} / \mathrm{s}$ & $4.32 \pm 1.55$ & $0.33 \pm 0.15$ & $0.5 \pm 0.1$ & $0.32 \pm 0.07$ & $0.2 \pm 0.05$ \\
\hline $\mathrm{FEF}_{25-75}, \%$ pred & $92 \pm 32$ & $13 \pm 6.5$ & $20.6 \pm 4.3$ & $12.4 \pm 3.3$ & $6.9 \pm 1.9$ \\
\hline ERV, L & $1.28 \pm 0.55$ & $0.76 \pm 0.31$ & $0.96 \pm 0.4$ & $0.67 \pm 0.3$ & $0.8 \pm 0.3$ \\
\hline IC, L & $3.26 \pm 1.01$ & $1.54 \pm 0.41$ & $2.19 \pm 0.3^{*}$ & $1.53 \pm 0.3 \dagger=$ & $1.24 \pm 0.2 \dagger$ \\
\hline $\mathrm{VC}, \mathrm{L}$ & $4.52 \pm 1.4$ & $2.23 \pm 0.62$ & $2.9 \pm 0.5$ & $2.14 \pm 0.57$ & $1.9 \pm 0.5$ \\
\hline $\mathrm{VC}, \%$ & $101 \pm 32$ & $75 \pm 19$ & $86.4 \pm 5.63$ & $73.8 \pm 20.4$ & $58 \pm 12$ \\
\hline IRV, L & $2.48 \pm 0.9$ & $0.78 \pm 0.29$ & $1.13 \pm 0.36$ & $0.80 \pm 0.3$ & $0.6 \pm 0.2$ \\
\hline $\mathrm{V}_{\mathrm{T}}, \mathrm{L}$ & $0.77 \pm 0.3$ & $0.73 \pm 0.23$ & 0.97 & $0.7 \pm 0.18$ & $0.63 \pm 0.15$ \\
\hline $\mathrm{D}_{\mathrm{LCO}}, \%$ pred & $80 \pm 12$ & $37.3 \pm 15.5$ & $35.5 \pm 31.5$ & $43.4 \pm 13.3$ & $25 \pm 5.6$ \\
\hline $\mathrm{TGV}, \mathrm{L}$ & $3.7 \pm 1$ & $5.5 \pm 1.9$ & $5.39 \pm 1.0$ & $5.18 \pm 1.9$ & $6.41 \pm 1.35$ \\
\hline $\mathrm{TGV}, \%$ pred & $124 \pm 27.6$ & $170 \pm 50$ & $168.6 \pm 51$ & $172 \pm 51$ & $200 \pm 40$ \\
\hline TLC, L & $6.6 \pm 2$ & $6.95 \pm 2$ & $7.55 \pm 1.2$ & $6.72 \pm 2$ & $7.6 \pm 1.7$ \\
\hline TLC, $\%$ pred & $112 \pm 19$ & $123.5 \pm 26.9$ & $121 \pm 19$ & $127 \pm 30$ & $133 \pm 24$ \\
\hline $\mathrm{RV}, \mathrm{L}$ & $2 \pm 0.7$ & $4.9 \pm 1.7$ & $4.9 \pm 1.1$ & $4.6 \pm 1.6$ & $5.85 \pm 1.62$ \\
\hline $\mathrm{RV}, \%$ pred & $115 \pm 45$ & $208 \pm 75$ & $186 \pm 40.6$ & $212 \pm 65$ & $262 \pm 83$ \\
\hline RV:TLC, \% & $28.5 \pm 7$ & $69.4 \pm 9.2$ & $64.3 \pm 6.3$ & $68 \pm 7$ & $76 \pm 6$ \\
\hline IC:TLC, \% & $47.5 \pm 8$ & $22.6 \pm 7$ & $28.2 \pm 5$ & $23.9 \pm 5$ & $16.7 \pm 3$ \\
\hline \multicolumn{6}{|c|}{ Diaphragmatic mobility, mean \pm SD } \\
\hline Rest breathing (mean), cm & $1.27 \pm 0.3$ & $2.09 \pm 0.8$ & $2.74 \pm 0.7 \dagger$ & $1.95 \pm 0.8 末$ & $2.52 \pm 0.6 \dagger$ \\
\hline Deep inspiration, $\mathrm{cm}$ & $6.93 \pm 1.15$ & $4.75 \pm 1.58$ & $5.61 \pm 1.6 \S$ & $4.4 \pm 1.7 \dagger$ & $4.6 \pm 2 \ddagger$ \\
\hline 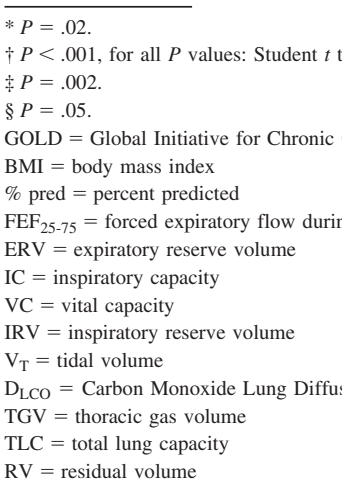 & $\begin{array}{l}\text { groups with health } \\
\text { ease. GOLD 2: } 50 \% \\
\text { the FVC maneuver }\end{array}$ & $\begin{array}{l}\text { uals. } \\
<80 \% \text {, GOLD 3: }\end{array}$ & $\mathrm{EV}_{1}<50 \%, \mathrm{GOLD}$ & $30 \%$ & \\
\hline
\end{tabular}

the pulmonary rehabilitation ranged from 0.95 to 0.98 , and the standard error of measurement ranged from 1.16 to $1.85 \mathrm{~cm}$ for the assessment before and after the pulmonary rehabilitation, respectively, in comparisons of the mean value for the 3 movements recorded. The test-retest bias was -0.06 , with $95 \%$ limits of agreement that ranged 
Table 2. Six-Min Walk Test for All the Subjects With COPD and for the Subjects Who Completed Pulmonary Rehabilitation, According to Airflow Limitation Severity

\begin{tabular}{|c|c|c|c|c|}
\hline \multirow{2}{*}{ Variable } & \multirow{2}{*}{$\begin{array}{l}\text { All Subjects With } \\
\text { COPD }(n=46)\end{array}$} & \multicolumn{3}{|c|}{$\begin{array}{l}\text { Subjects Who Completed } \\
\text { Pulmonary Rehabilitation }(n=30)\end{array}$} \\
\hline & & GOLD 2 & GOLD 3 & GOLD 4 \\
\hline Subjects, $n$ (women) & $46(11)$ & $6(0)$ & $13(6)$ & $11(1)$ \\
\hline $\mathrm{S}_{\mathrm{pO}_{2}}(\%)$, mean $\pm \mathrm{SD}$ & $89 \pm 7$ & $87 \pm 13$ & $90 \pm 5$ & $87 \pm 8$ \\
\hline $\mathrm{HR}$, mean $\pm \mathrm{SD}$ beats $/ \mathrm{min}$ & $108 \pm 14$ & $104 \pm 16$ & $110 \pm 9$ & $117 \pm 10$ \\
\hline $\mathrm{f}$, breaths/min mean $\pm \mathrm{SD}$ breaths $/ \mathrm{min}$ & $26 \pm 5$ & $25 \pm 5$ & $18 \pm 3$ & $26 \pm 5$ \\
\hline MBS dyspnea, mean $\pm \mathrm{SD}$ & $4 \pm 2$ & $1.7 \pm 1.5$ & $4 \pm 3$ & $6 \pm 2$ \\
\hline MBS muscle, mean $\pm \mathrm{SD}$ & $4 \pm 3$ & $3 \pm 1.5$ & $3 \pm 3$ & $5.7 \pm 3$ \\
\hline Distance walked, mean $\pm \mathrm{SD} \mathrm{m}$ & $235 \pm 103$ & $240 \pm 93$ & $288 \pm 101$ & $160 \pm 47$ \\
\hline Distance walked, mean $\pm \mathrm{SD} \%$ predicted & $50 \pm 23$ & $52 \pm 12$ & $59 \pm 25$ & $31 \pm 14$ \\
\hline \multicolumn{5}{|c|}{$\begin{array}{l}\text { GOLD }=\text { Global Initiative for Chronic Obstructive Lung Disease. GOLD 2: } 50 \%<\mathrm{FEV}_{1}<80 \%, \mathrm{GOLD} 3: 30 \%<\mathrm{FEV}_{1}<50 \%, \mathrm{GOLD}_{4}: \mathrm{FEV}_{1}<30 \% \\
\mathrm{HR}=\text { Heart rate } \\
\text { MBS = modified Borg scale }\end{array}$} \\
\hline
\end{tabular}

from -0.23 to 0.93 , and standards error of measurements of 0.47 .

\section{Discussion}

The main results of our research can be summarized as follows. First, the diaphragmatic mobility demonstrated significant differences between the subjects with COPD and the healthy controls. During resting breathing, mobility was statistically and clinically higher, especially at the beginning of the rehabilitation program, without improvements thereafter. Diaphragmatic mobility during deep inspiration was lower than in the healthy controls, but improved after rehabilitation, and those improvements were followed by improvements of the inspiratory capacity. Second, diaphragmatic mobility reduction was correlated to loss in lung function.

\section{Diaphragmatic Mobility Modifications During Rest Breathing}

In our study, diaphragmatic mobility recorded during rest breathing by M-mode ultrasonography was higher in the subjects with COPD than in the controls. The increase in diaphragmatic mobility during rest breathing was consistent with the inspiratory effort increase caused by lung hyperinflation as verified on the lung function tests. In these circumstances, end-expiratory lung volume was above the relaxation volume, which resulted in an intrinsic PEEP that needed to be overcome by the inspiratory muscles before inspiratory flow could start. Research from Similowski et al ${ }^{30}$ demonstrated, through measurements of transdiaphragmatic pressure in stable COPD subjects, that the diaphragmatic ability to transform the transdiaphrag- matic pressure into an inspiratory fall in intrathoracic pressure, decreased similarly with increasing lung volumes in healthy individuals and subjects with COPD. This finding indicated that diaphragmatic strength was restored by a compensatory mechanism.

Besides the fact that, in Similowski's study, the diaphragmatic mobility was not assessed, it is possible to presume that those compensatory mechanisms may restore the diaphragmatic strength in a COPD subject. Furthermore, an in vivo study also demonstrated that the average diaphragmatic isometric tension or average peak force in subjects with COPD is similar to those found in healthy individuals. ${ }^{9}$

Diaphragmatic mobility under an increased respiratory load was described by using M-mode ultrasonography in healthy individuals and it was reported as an increase in the diaphragmatic excursions during rest breathing, from (mean $\pm \mathrm{SD}$ ) $1.7 \pm 0.5 \mathrm{~cm}$ to $2.1 \pm 0.9 \mathrm{~cm},{ }^{31}$ so it is not surprising that, in our study, diaphragmatic mobility at rest was higher in the subjects with COPD compared with the healthy individuals. Also, the inverse correlation between the $\mathrm{FEV}_{1} \%$ predicted and the diaphragmatic mobility at rest breathing supported the relationship between the severity of airway obstruction and the inspiratory work of the diaphragm.

\section{Diaphragmatic Mobility Modifications During Deep Inspiration}

Diaphragmatic mobility during deep inspiration contrasted with the mobility during rest breathing. It was lower in the subjects with COPD when compared with the healthy controls. This decrease seemed to be related to COPD severity, and, indeed, our study identified an inverse cor- 
Table 3. Comparisons on Lung Function Tests, Arterial Blood Gas Analyses, 6-Min Walking Test, and Diaphragmatic Ultrasonography on All Subjects With COPD Who Completed the Rehabilitation Program

\begin{tabular}{|c|c|c|}
\hline \multirow{2}{*}{ Variable } & \multicolumn{2}{|c|}{ Pulmonary Rehabilitation } \\
\hline & Before & After \\
\hline \multicolumn{3}{|l|}{ Lung function } \\
\hline FVC, L & $2.07 \pm 0.7$ & $2.16 \pm 0.8$ \\
\hline FVC, $\%$ pred & $70 \pm 18$ & $73 \pm 20$ \\
\hline $\mathrm{FEV}_{1}, \mathrm{~L}$ & $0.9 \pm 0.5$ & $0.97 \pm 0.5$ \\
\hline $\mathrm{FEV}_{1}, \%$ pred & $40 \pm 18$ & $42 \pm 21$ \\
\hline FVC:FEV 1 & $44 \pm 15$ & $44 \pm 14$ \\
\hline $\mathrm{IC}, \mathrm{L}$ & $1.58 \pm 0.5$ & $1.7 \pm 0.6^{*}$ \\
\hline $\mathrm{VC}, \mathrm{L}$ & $2.2 \pm 0.7$ & $2.3 \pm 0.7$ \\
\hline $\mathrm{VC}, \%$ pred & $73 \pm 19$ & $76 \pm 21$ \\
\hline TLC, L & $7.1 \pm 2$ & $7.1 \pm 2$ \\
\hline TLC, $\%$ pred & $127 \pm 26$ & $133 \pm 40$ \\
\hline $\mathrm{RV}, \mathrm{L}$ & $5.07 \pm 1.6$ & $5.06 \pm 1.7$ \\
\hline $\mathrm{RV}, \%$ pred & $222 \pm 74$ & $221 \pm 76$ \\
\hline RV:TLC, \% & $70 \pm 8$ & $70 \pm 10$ \\
\hline IC:TLC, \% & $22.6 \pm 7$ & $25 \pm 6$ \\
\hline \multicolumn{3}{|l|}{ Arterial blood gas analyses } \\
\hline $\mathrm{pH}$ & $7.43 \pm 0.03$ & $7.43 \pm 0.03$ \\
\hline $\mathrm{P}_{\mathrm{aO}_{2}}, \mathrm{~mm} \mathrm{Hg}$ & $78 \pm 15$ & $70 \pm 10 *$ \\
\hline $\mathrm{P}_{\mathrm{aCO}_{2}}, \mathrm{~mm} \mathrm{Hg}$ & $44 \pm 12$ & $41 \pm 7$ \\
\hline $\mathrm{HCO}_{3}, \mathrm{~mm} \mathrm{Hg}$ & $28 \pm 4$ & $27 \pm 3$ \\
\hline $\mathrm{S}_{\mathrm{pO}_{2}}, \%$ & $95 \pm 2$ & $94 \pm 2 \dagger$ \\
\hline Oxygen flow, $\mathrm{L} / \mathrm{min}$ & $2 \pm 1$ & $1 \pm 1.5$ \\
\hline \multicolumn{3}{|l|}{ 6-min walk test } \\
\hline $\mathrm{S}_{\mathrm{pO}_{2}}(\%)$ & $89 \pm 8$ & $90 \pm 7$ \\
\hline $\mathrm{HR}$, beats/min & $110 \pm 13$ & $109 \pm 12$ \\
\hline $\mathrm{f}$, breaths/min & $27 \pm 7$ & $24 \pm 6$ \\
\hline MBS dyspnea & $4 \pm 3$ & $3.5 \pm 2$ \\
\hline MBS muscle & $4 \pm 3$ & $3 \pm 2$ \\
\hline Distance walked, $\mathrm{m}$ & $226 \pm 95$ & $280 \pm 80 \dagger$ \\
\hline Distance walked, $\%$ pred & $48 \pm 22$ & $60 \pm 21$ \\
\hline \multicolumn{3}{|l|}{ Diaphragmatic mobility } \\
\hline Rest breathing, cm & $2.25 \pm 0.83$ & $2.53 \pm 0.82$ \\
\hline Deep inspiration, $\mathrm{cm}$ & $4.58 \pm 1.83$ & $5.45 \pm 1.56$ \\
\hline \multicolumn{3}{|l|}{$n=30}$. \\
\hline \multicolumn{3}{|l|}{ Data are mean \pm SD. } \\
\hline \multicolumn{3}{|l|}{$* P=.04$} \\
\hline \multirow{2}{*}{\multicolumn{3}{|c|}{$\begin{array}{l}\ddagger P=.01, P \text { values for Student } t \text { test } \\
\% \text { pred }=\text { percent predicted }\end{array}$}} \\
\hline \multirow{2}{*}{\multicolumn{3}{|c|}{$\begin{array}{l}\% \text { pred }=\text { percent predicted } \\
\text { IC = inspiratory capacity }\end{array}$}} \\
\hline & & \\
\hline \multicolumn{3}{|l|}{$\mathrm{VC}=$ vital capacity } \\
\hline \multicolumn{3}{|l|}{$\mathrm{TLC}=$ total lung capacity } \\
\hline \multicolumn{3}{|l|}{$\mathrm{RV}=$ residual volume } \\
\hline \multicolumn{3}{|l|}{$\mathrm{HR}=$ heart rate } \\
\hline $\mathrm{f}=$ breathing frequency & & \\
\hline MBS $=$ modified Borg scale & & \\
\hline
\end{tabular}

relation between diaphragmatic mobility during deep inspiration and COPD severity. Furthermore, the correlation between the diaphragmatic mobility and the lung function test was positive between deep inspiration and the inspiratory capacity, expiratory reserve volume, and the inspira- tory capacity to total lung capacity ratio. These results agreed with previous findings, in which the diaphragmatic mobility reduction was associated with emphysema severity ${ }^{32}$ These results agreed with previous findings, recorded on B-mode ultrasonography, which demonstrated a reduction of diaphragmatic mobility on inspiratory and expiratory forced breathing in subjects with COPD. ${ }^{18}$ It was also demonstrated that the subjects with COPD who were severely hyperinflated had less diaphragmatic mobility than the healthy individuals and that this impairment was strongly associated with static air trapping measured by the residual volume to total lung capacity ratio. ${ }^{19}$ With regard to deep inspiration, our results also agreed with a recent systematic review, which demonstrated that diaphragmatic mobility pathologic values are lower. ${ }^{33}$

The results of the pulmonary function test, in which the total lung capacity was (mean $\pm \mathrm{SD}$ ) $124 \pm 27 \%$ predicted value and residual volume was (mean \pm SD) $208 \pm 75 \%$ predicted suggested that our subjects with COPD had static pulmonary gas trapping, and the impact of dynamic lung hyperinflation on diaphragmatic mobility was demonstrated by the positive correlation between the diaphragmatic mobility during deep inspiration and both inspiratory capacity and the inspiratory capacity to total lung capacity ratio (Figs. 3 and 4).

\section{Rehabilitation Effect on the Diaphragmatic Mobility}

Pulmonary rehabilitation provides several improvements to patients with COPD, especially in quality of life and tolerance to exercises. ${ }^{34}$ However, there is an important lack of information on the effect of pulmonary rehabilitation on other functional outcomes. To our knowledge, this was the first study that assessed the impact of pulmonary rehabilitation on diaphragmatic mobility by using M-mode ultrasonography. Previously, diaphragmatic mobility was assessed with fluoroscopy, in which the investigators also found increased diaphragmatic mobility during deep inspirations after pulmonary rehabilitation, but those findings were expressed in $\mathrm{mm}^{2}$, so it was not possible to extrapolate their findings from the results that we observed on the direct measurement of the diaphragmatic dome displacement. ${ }^{35}$

In our study, the subjects who completed pulmonary rehabilitation increased their diaphragmatic mobility only during deep inspiration, without any differences at rest breathing. The increase was not only statistically but also clinically important and ranged from (mean \pm SD) $4.58 \pm 1.83 \mathrm{~cm}$ to $($ mean $\pm \mathrm{SD}$ ) $5.45 \pm 1.56 \mathrm{~cm}$, which increased more than $1 \mathrm{~cm}$ on its maximal excursion, with low effect size, and which surpassed the normal values stated in previous reports ${ }^{13,36}$ and confirmed in our study. So we can state that diaphragmatic mobility assessment plays a role not only in the muscle mobility, but also 

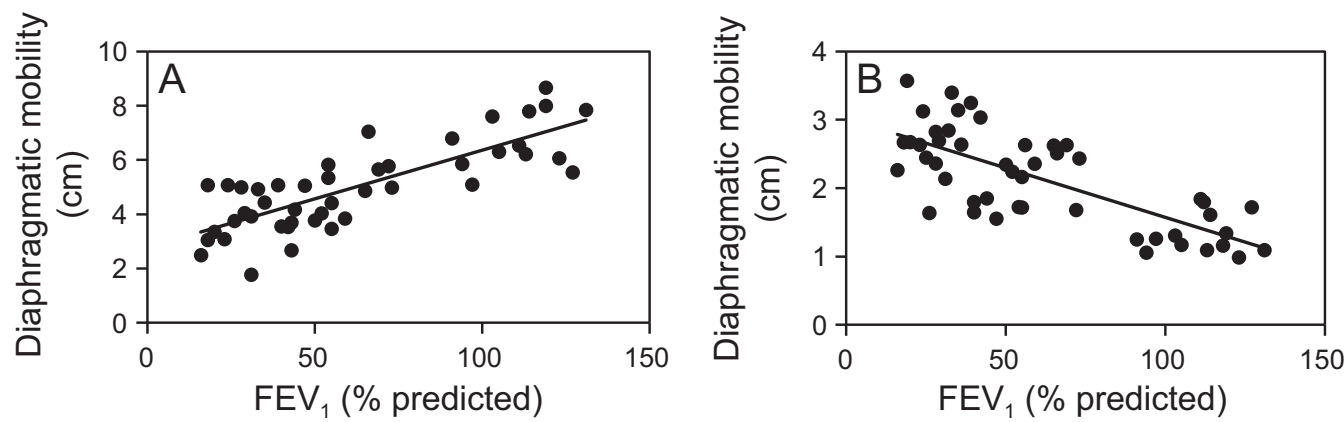

Fig. 3. The correlation between the diaphragmatic mobility and the $\mathrm{FEV}_{1} \%$ predicted. Deep inspiration $(r=-0.74, P<.001)(\mathrm{A})$; at rest breathing $(r=-0.8, P<.001)(B)$.
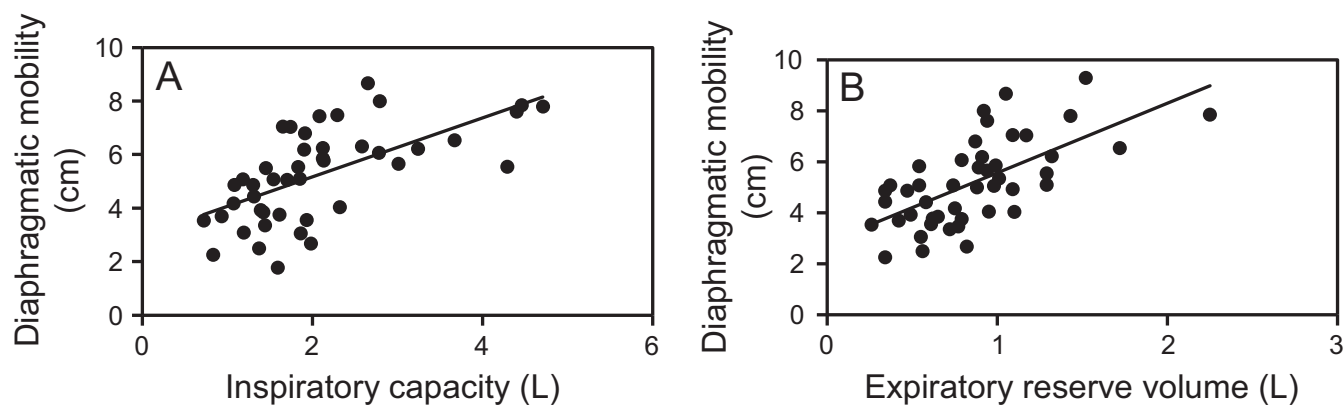

Fig. 4. The correlation between the diaphragmatic mobility during deep inspiration with inspiratory capacity $(r=-0.64, P<.001)(A)$, and expiratory reserve volume $(r=-0.63, P<.001)(B)$.
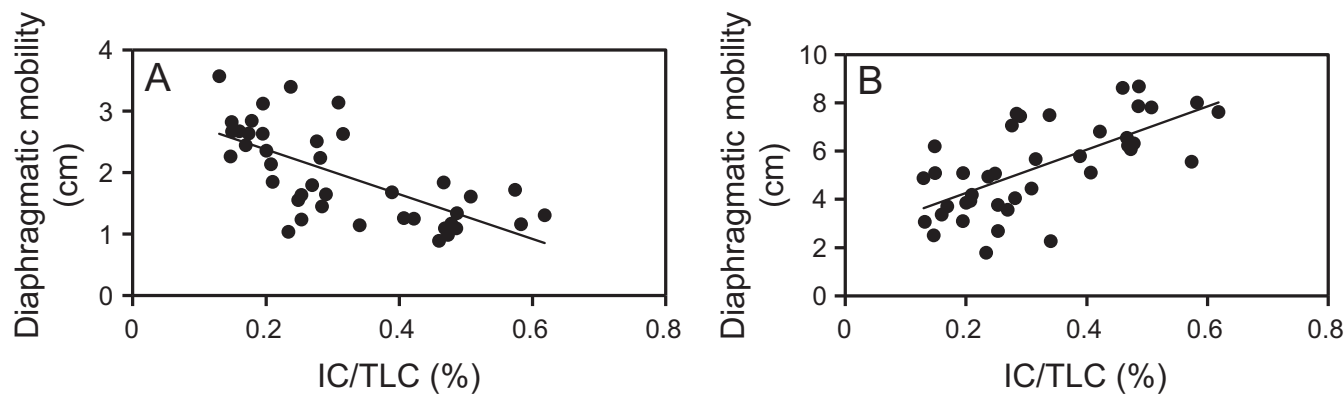

Fig. 5. The correlation between the diaphragmatic mobility during rest breathing with inspiratory capacity to total lung capacity (IC/TLC) ratio $(r=0.51, P=.01)(A)$; and during deep inspiration with IC/TLC $(B)(r=0.5, P=.01)$.

demonstrates the reduction of dynamic hyperinflation in subjects with severe and very-severe airway obstruction.

The loss of diaphragmatic mobility may not just represent a mechanical respiratory impairment. In patients with severe and very-severe COPD, the level of diaphragmatic mobility dysfunction may also represent a higher risk of death. ${ }^{37}$ It is known that diaphragmatic ultrasonography, in both B- and M-mode, may not replace body plethysmography to determine COPD severity, ${ }^{11}$ but the addition of this information in the rehabilitation process may help health professionals to better understand the functional impact of diaphragmatic dysfunction.

Diaphragmatic dysfunction is defined as an expression of reduction of the physical capacity and of the presence of air trapping, besides pulmonary hyperinflation. ${ }^{18}$ Because we verified that that our sample presented inspiratory capacity increases that were correlated to diaphragmatic mobility improvements during deep inspirations, we demonstrated that it was possible to determine whether this improved their dynamic hyperinflation after pulmonary rehabilitation.

Therefore, we demonstrated that this dysfunction can be reverted, especially in subjects with severe airway obstruction, as previously published. ${ }^{35}$ Furthermore, M-mode ultrasonography had the advantage that our subjects were not exposed to ionization. The assessment after a COPD diagnosis is important to determine functional impairment. There are still many questions to be answered, and the search for other feasible outcomes is needed and also rec- 
ommended. ${ }^{38}$ In this context, we believed that such assessment, especially during rehabilitation, provided relevant functional and clinical outcomes to manage the patient with COPD.

Even though current literature on diaphragmatic mobility in healthy subjects is not consensual regarding the mean values for rest breathing and deep inspiration motion, ${ }^{36}$ it was imperative to verify those outcomes to establish real parameters to determine the differences between healthy and COPD subjects. In our research, the healthy subjects presented values statistically similar to those found in previous papers that determined normal values for rest breathing and deep inspiration when using the same protocol, ${ }^{13,36}$ with a slight physiologic difference during rest breathing (a lower mean value that can be considered similar when considering the SD), explainable by the sample size. Other trials reported different values, especially for the diaphragmatic mobility at total lung capacity, but those studies had different methods, purposes, and populations. ${ }^{11,38-43} \mathrm{We}$ also confirmed the intra-examiner variability lower than $5 \%$ reported by Testa et $\mathrm{al}^{36}$ for the measurements of the diaphragmatic mobility on rest breathing for all subjects with COPD, which demonstrated the reliability and reproducibility of this measurement in such subjects.

\section{Study Limits}

The main limitation of our study was the design. Because it was an observational study, it was not possible to compare with a group with no pulmonary rehabilitation. As we see, it is more than a design limitation, but a ethical issue not possible to cross because we do not feel to untreat subjects with COPD, eligible to perform the pulmonary rehabilitation, after its exacerbation. The age difference between the subjects with COPD and the healthy individuals could be considered a limitation; nevertheless, previous studies on diaphragmatic mobility ${ }^{13,36}$ demonstrated no correlation between age and diaphragmatic mobility. Our methods did not allow us to establish new parameters, specifically to assess lung function, nor to make any new cutoff points to determine respiratory distress, and we think that these limitations may be another frontier to be crossed.

\section{Conclusions}

In this research, the ultrasonography on M-mode provided relevant information regarding the influence of severe COPD on diaphragmatic mobility. Our results supported previous findings that COPD alters diaphragmatic function. The decrease in diaphragmatic mobility during slow deep inspirations could be improved by pulmonary rehabilitation, and this result was associated with improvements in lung function tests. Our methods and sample size enabled us to state that ultrasonography on M-mode can provide important reproducible information regarding the diaphragm mobility.

\section{ACKNOWLEDGMENTS}

The authors thank Antonella Novo, Marina Canta, Ennio Nardullo, and the physiotherapy team from Casa di Cura Villa Serena who gave structural and technical support for this research.

\section{REFERENCES}

1. Gea J, Agustí A, Roca J. Pathophysiology of muscle dysfunction in COPD. J Appl Physiol 2013;114(9):1222-1234.

2. Global Initiative for Chronic Obstructive Lung. From the Global Strategy for the Diagnosis, Management and Prevention of COPD, Global Initiative for Chronic Obstructive Lung Disease (GOLD) 2017. http://goldcopd.org. 2017. Assessed May 2, 2017.

3. Viegi G, Pistelli F, Sherrill DL, Maio S, Baldacci S, Carrozzi L. Definition, epidemiology and natural history of COPD. Eur Respir J 2007;30(5):993-1013.

4. Ferguson GT. Why does the lung hyperinflate? Proc Am Thorac Soc 2006;3(2):176-179.

5. Donaldson AV, Maddocks M, Martolini D, Polkey MI, Man WD. Muscle function in COPD: a complex interplay. Int J Chron Obstruct Pulmon Dis 2012;7:523-535.

6. De Troyer A. Effect of hyperinflation on the diaphragm. Eur Respir J 1997;10(3):708-713.

7. Cassart M, Pettiaux N, Gevenois PA, Paiva M, Estenne M. Effect of chronic hyperinflation on diaphragm length and surface area. Am J Respir Crit Care Med 1997;156(2 Pt 1):504-508.

8. Ottenheijm CA, Heunks LM, Dekhuijzen PN. Diaphragm muscle fiber dysfunction in chronic obstructive pulmonary disease: toward a pathophysiological concept. Am J Respir Crit Care Med 2007; 175(12):1233-1240.

9. Stubbings AK, Moore AJ, Dusmet M, Goldstraw P, West TG, Polkey MI, Ferenczi MA. Physiological properties of human diaphragm muscle fibres and the effect of chronic obstructive pulmonary disease. J Physiol 2008;586(10):2637-2650.

10. Sarwal A, Walker FO, Cartwright MS. Neuromuscular ultrasound for evaluation of the diaphragm. Muscle Nerve 2013;47(3):319-329.

11. Scott S, Fuld JP, Carter R, McEntegart M, MacFarlane NG. Diaphragm ultrasonography as an alternative to whole-body plethysmography in pulmonary function testing. J Ultrasound Med 2006; 25(2):225-232.

12. Connolly AM, Mittendorfer B. Tracking diaphragm movement by using ultrasound to assess its strength. J Physiol 2016;594(24):71477148.

13. Boussuges A, Gole Y, Blanc P. Diaphragmatic motion studied by m-mode ultrasonography: methods, reproducibility, and normal values. Chest 2009;135(2):391-400.

14. Toledo NS, Kodaira SK, Massarollo PC, Pereira OI, Mies S. Right hemidiaphragmatic mobility: assessment with US measurement of craniocaudal displacement of left branches of portal vein. Radiology 2003;228(2):389-394.

15. Spruit MA, Singh SJ, Garvey C, ZuWallack R, Nici L, Rochester C, et al; ATS/ERS Task Force on Pulmonary Rehabilitation. An official American Thoracic Society/European Respiratory Society statement: key concepts and advances in pulmonary rehabilitation. Am J Respir Crit Care Med 2013;188(8):e13-64.

16. Altenburg WA, de Greef MH, ten Hacken NH, Wempe JB. A better response in exercise capacity after pulmonary rehabilitation in more severe COPD patients. Respir Med 2012;106(5):694-700. 


\section{Pulmonary Rehab for Diaphragmatic Mobility Loss}

17. Lötters F, van Tol B, Kwakkel G, Gosselink R. Effects of controlled inspiratory muscle training in patients with COPD: a meta-analysis. Eur Respir J 2002;20(3):570-576.

18. Paulin E, Yamaguti WP, Chammas MC, Shibao S, Stelmach R, Cukier A, Carvalho CR. Influence of diaphragmatic mobility on exercise tolerance and dyspnea in patients with COPD. Respir Med 2007;101(10):2113-2118.

19. Dos Santos Yamaguti WP, Paulin E, Shibao S, Chammas MC, Salge $\mathrm{JM}$, Ribeiro M, et al. Air trapping: The major factor limiting diaphragm mobility in chronic obstructive pulmonary disease patients. Respirology 2008;13(1):138-144.

20. Jung KJ, Park JY, Hwang DW, Kim JH, Kim JH. Ultrasonographic diaphragmatic motion analysis and its correlation with pulmonary function in hemiplegic stroke patients. Ann Rehabil Med 2014;38(1): 29-37.

21. Pellegrino R, Viegi G, Brusasco V, Crapo RO, Burgos F, Casaburi $\mathrm{R}$, et al. Interpretative strategies for lung function tests. Eur Respir J 2005;26(5):948-968.

22. Miller MR, Crapo R, Hankinson J, Brusasco V, Burgos F, Casaburi $\mathrm{R}$, et al; ATS/ERS Task Force. General considerations for lung function testing. Eur Respir J 2005;26(1):153-161.

23. Miller MR, Hankinson J, Brusasco V, Burgos F, Casaburi R, Coates A, et al; ATS/ERS Task Force. Standardisation of spirometry. Eur Respir J 2005;26(2):319-338.

24. Wanger J, Clausen JL, Coates A, Pedersen OF, Brusasco V, Burgos F, et al. Standardisation of the measurement of lung volumes. Eur Respir J 2005;26(3):511-522.

25. Macintyre N, Crapo RO, Viegi G, Johnson DC, van der Grinten CP, Brusasco V, et al. Standardisation of the single-breath determination of carbon monoxide uptake in the lung. Eur Respir J 2005;26(4): 720-735.

26. Enright PL, Sherrill DL. Reference equations for the six-minute walk in healthy adults. Am J Respir Crit Care Med 1998;158(5 Pt 1): 1384-1387.

27. Enright PL, McBurnie MA, Bittner V, Tracy RP, McNamara R, Arnold A, Newman AB; Cardiovascular Health Study. The 6-min walk test: a quick measure of functional status in elderly adults. Chest 2003;123(2):387-398.

28. Spruit MA, Singh SJ, Garvey C, ZuWallack R, Nici L, Rochester C, et al; ATS/ERS Task Force on Pulmonary Rehabilitation. An official American Thoracic Society/European Respiratory Society statement: key concepts and advances in pulmonary rehabilitation. Am J Respir Crit Care Med 2013;188(8):e13-64.

29. World Medical Association Declaration of Helsinki. Ethical principles for medical research involving human subjects. Bull World Health Organ. 2001;79(4):373-374.

30. Similowski T, Yan S, Gauthier AP, Macklem PT, Bellemare F. Contractile properties of the human diaphragm during chronic hyperinflation. N Engl J Med 1991;325(13):917-923.
31. Soilemezi E, Tsagourias M, Talias MA, Soteriades ES, Makrakis V, Zakynthinos E, Matamis D. Sonographic assessment of changes in diaphragmatic kinetics induced by inspiratory resistive loading. Respirology 2013;18(3):468-473.

32. He L, Zhang W, Zhang J, Cao L, Gong L, Ma J, et al. Diaphragmatic motion studied by M-mode ultrasonography in combined pulmonary fibrosis and emphysema. Lung 2014;192(4):553-561.

33. Sferrazza Papa GF, Pellegrino GM, Di Marco F, Imeri G, Brochard L, Goligher E, Centanni S. A Review of the Ultrasound Assessment of Diaphragmatic Function in Clinical Practice. Respiration 2016; 91(5):403-411.

34. Singh SJ, Puhan MA, Andrianopoulos V, Hernandes NA, Mitchell $\mathrm{KE}$, Hill CJ, et al. An official systematic review of the European Respiratory Society/American Thoracic Society: measurement properties of field walking tests in chronic respiratory disease. Eur Respir J 2014;44(6):1447-1478.

35. Chun EM, Han SJ, Modi HN. Analysis of diaphragmatic movement before and after pulmonary rehabilitation using fluoroscopy imaging in patients with COPD. Int J Chron Obstruct Pulmon Dis 2015;10: 193-199.

36. Testa A, Soldati G, Giannuzzi R, Berardi S, Portale G, Gentiloni Silveri N. Ultrasound M-mode assessment of diaphragmatic kinetics by anterior transverse scanning in healthy subjects. Ultrasound Med Biol 2011;37(1):44-52.

37. Yamaguti WP, Paulin E, Salge JM, Chammas MC, Cukier A, Fernandes Carvalho CR. Diaphragmatic dysfunction and mortality in patients with COPD. J Bras Pneumol 2009;35(12):1174-1181.

38. Celli BR, Decramer M, Wedzicha JA, Wilson KC, Agustí A, Criner GJ, et al. An Official American Thoracic Society/European Respiratory Society Statement: Research questions in chronic obstructive pulmonary disease. Am J Respir Crit Care Med 2015;191(7):e4-e27.

39. Cohen E, Mier A, Heywood P, Murphy K, Boultbee J, Guz A. Excursion-volume relation of the right hemidiaphragm measured by ultrasonography and respiratory airflow measurements. Thorax 1994; 49(9):885-889.

40. Houston JG, Fleet M, Cowan MD, McMillan NC. Comparison of ultrasound with fluoroscopy in the assessment of suspected hemidiaphragmatic movement abnormality. Clin Radiol 1995;50(2):95-98.

41. Houston JG, Angus RM, Cowan MD, McMillan NC, Thomson NC. Ultrasound assessment of normal hemidiaphragmatic movement: relation to inspiratory volume. Thorax 1994;49(5):500-503.

42. Ayoub J, Cohendy R, Dauzat M, Targhetta R, De la Coussaye JE, Bourgeois JM, et al. Non-invasive quantification of diaphragm kinetics using m-mode sonography. Can J Anaesth 1997;44(7):739744.

43. Targhetta R, Chavagneux R, Ayoub J, Lemerre C, Préfaut C, Bourgeois JM, Balmes P. [Right diaphragmatic kinetics measured by TM-mode ultrasonography with concomitant spirometry in normal subjects and asthmatic patients. Preliminary results]. Rev Med Interne $1995 ; 16(11): 819-826$. 